\title{
Retos actuales en la implementación de la ley sobre refugiados y protección complementaria en México: identificación, admisión y acceso al procedimiento de asilo
}

\author{
Current Challenges in the Implementation \\ of the Law on Refugees and Complementary \\ Protection in Mexico: Identification, Admission \\ and Access to the Asylum Procedure
}

Sergio Alejandro REA Granados*

SUMARIO: I. Introducción. II. Antecedentes. III. México y la migración internacional.IV. Identificación de personas que requieren protección internacional. V. Derecho al acceso al procedimiento para solicitar asilo. VI. Acceso al territorio apersonas necesitadas deprotección internacional.VII. Conclusión. VIII. Bibliografía.

* Doctorando en la Universidad de Chile. Maestría en la Universidad de Melbourne, Australia. Licenciado en Derecho, Universidad Iberoamericana, Ciudad de México.

Artículo recibido el 3 de diciembre de 2014 Aprobado para publicación el 31 de agosto de 2015 
RESUMEN: Este ensayo tiene por objeto analizar los retos actuales que enfrenta el Estado mexicano en materia de implementación del derecho internacional de los refugiados ante un flujo migratorio mixto en relación con la identificación, admisión y acceso al procedimiento de asilo de posibles solicitantes de la condición de refugiado.

Palabras clave: solicitantes de asilo, flujos migratorios mixtos, México, derecho internacional de los refugiados, identificación, admisión y acceso al procedimiento.

ABSTRACT: This paper aims to analyze the current challenges that the Mexican State is facing regarding the implementation of international refugee law among a mixed migration flows in relation to identification, admission and access to the asylum procedure of potential applicants for refugee status.

Key words: Asylum seekers, mix migration flows, Mexico, international refugee law, identification, admission and access to the asylum procedure.

RÉSUMÉ: Ce document vise à examiner les défis actuels rencontrés par le gouvernement mexicain dans la mise en œuvre du droit international des réfugiés à un flux migratoire mixte par rapport à l'identification, l'admission et l'accès à la procédure d'asile pour les candidats potentiels au statut de réfugié.

Mots-clés: Les demandeurs d'asile, la migration mixte, le Mexique, le droit international des réfugiés, l'identification, l'admission et l'accès à la procédure. 


\section{INTRODUCCIÓN}

México ha sido reconocido a nivel internacional por su tradición de asilo, por ejemplo en el siglo XIX el gobierno mexicano brindó protección a miembros del grupo originario Kikapú, quienes huían de la persecución que enfrentaban en Estados Unidos; ${ }^{1}$ posteriormente, en los años cuarenta, brindó protección a los españoles que escapaban de la Guerra Civil; en los setenta, a los sudamericanos que escapaban de las dictaduras, y, finalmente, el último gran éxodo masivo hacia México se produjo en los años ochenta, durante los conflictos armados en Centroamérica. Actualmente, los flujos masivos de refugiados a México ya no se dan. Sin embargo, este país continúa recibiendo refugiados, aunque en un contexto y situación diferente a los de los hitos ya mencionados. La situación geográfica de México es un factor relevante para los flujos mixtos de migraciones, no sólo de personas provenientes de la región de Centroamérica sino también de otras latitudes. En la actualidad, dentro de estos flujos migratorios, existe un número importante de personas que escapan de su país de origen por persecución individualizada, o bien, por una situación objetiva, ya sea porque son amenazados ante la situación de un conflicto armado u otra circunstancia general grave que ponga en riesgo su vida, seguridad o libertad. Ante tal situación de persecución o riesgo de sus vidas, la mayoría de las veces, estas personas se ven en la necesidad de utilizar medios y rutas diversas, ya sea convencionales o irregulares, para llegar a o simplemente para transitar por México, cuya primera instancia, en diversos casos no es su primera elección. Este hecho provoca que la persona merecedora de protección internacional, en muchos de los casos, enfrente diversos obstáculos para ser identificados como tal y de esta manera, ser canalizados al procedimiento para ser reconocidos como refugiados.

A pesar que recientemente el Estado mexicano ha hecho esfuerzos importantes, en el ámbito legal, para fortalecer la institución del asilo, también es cierto que todavía existen grandes desafíos para que la ley sobre la materia se cumpla cabalmente y estén de acuerdo con las disposiciones del

1 Mager Hois, Elisabeth A., Kikapú: Pueblos Indígenas del México contemporáneo, México, Comisión Nacional para el Desarrollo de los Pueblos Indígenas, pp. 9-13. 
Esta revista forma parte del acervo de la Biblioteca Jurídica Virtual del Instituto de Investigaciones Jurídicas de la UNAM

derecho internacional de los refugiados. En este orden de ideas, este trabajo de investigación tiene la finalidad de conocer algunos de los desafíos que enfrenta la implementación de la Ley sobre Refugiados y Protección Complementaria en favor de las personas merecedoras de protección internacional en cuanto a su identificación, admisión y acceso al procedimiento de asilo al llegar o simplemente transitar por México.

\section{ANTECEDENTES}

En la historia de las civilizaciones la figura del asilo ha estado presente de una u otra forma. Esto debido a que las migraciones humanas son un fenómeno común en la historia del hombre y de su progreso cultural, y, en ese desarrollo, la gran mayoría de las culturas han debido efectuar o soportar movimientos migratorios por diversas razones, entre las que ciertamente se incluyen migrar por razones de persecución o por el hecho de hallarse en guerras que ponen en peligro la vida, libertad y seguridad de personas y pueblos.

La comunidad internacional comenzó a tomar en cuenta esta situación cuando el fenómeno de los refugiados se agudizó durante las dos guerras mundiales del siglo XX. ${ }^{2}$ Después de ambas guerras dejó como saldo no sólo a miles de muertos y heridos sino también a miles de personas desplazadas de sus lugares de origen, por lo tanto, el 14 de diciembre de 1950, la Asamblea General de las Naciones Unidas, mediante su resolución 428(V), acordó el funcionamiento de la Oficina de las Naciones Unidas para los Refugiados (ACNUR), órgano subsidiario con el mandato de proporcionar protección internacional a los refugiados en el mundo, además de asistir a los gobiernos y organizaciones privadas en la búsqueda de soluciones permanentes a la situación de los refugiados. ${ }^{3}$

En el caso mexicano, la oficina del ACNUR fue establecida en 1982, cuando el gobierno de México requirió el apoyo de esta agencia y cuya experiencia era necesaria para atender el flujo masivo de refugiados guate-

2 Ray Wilkinson, El asilo no tiene precio, vale tanto como la propia vida, http: / / www.acnur.org / t3/el-acnur/historia-del-acnur/el-asilo-no-tiene-precio-vale-tanto-como-la-propia-vida/.

3 ACNUR, Creación del ACNUR, http://www.acnur.org/t3/el-acnur/historia-del-acnur/ac nur-como-honrar-un-mandato/. 
Esta revista forma parte del acervo de la Biblioteca Jurídica Virtual del Instituto de Investigaciones Jurídicas de la UNAM

maltecos que escapaban del respectivo conflicto interno. Posteriormente y ante las nuevas realidades de la migración forzada, el ACNUR abrió una nueva oficina en la ciudad de Tapachula, Chiapas, al ser un lugar estratégico debido a la frontera existente con Guatemala, y además, por ser la principal entrada de migraciones irregulares ${ }^{4}$ al territorio mexicano. Actualmente el trabajo del ACNUR en México se enfoca en cabildear las pertinentes iniciativas de ley para que se ajusten a los estándares internacionales; proteger y garantizar el cumplimiento de la Convención de 1951 sobre el Estatuto de los Refugiados y su Protocolo de 1967; brindar asesoría técnica y jurídica al Estado mexicano sobre el derecho internacional de los refugiados y brindar capacitaciones técnicas a personas involucradas en el tema. ${ }^{5}$

Por otro lado, para atender las necesidades de los flujos masivos de refugiados en los años ochenta, el gobierno mexicano creó la Comisión Mexicana de Ayuda a Refugiados (Comar), un órgano intersecretarial dependiente de la Secretaría de Gobernación, con la finalidad de atender las necesidades de la población refugiada. ${ }^{6}$ Posteriormente, una vez ratificada la Convención de 1951 sobre el Estatuto de los Refugiados, ${ }^{7}$ a partir de 2002, la Comar comenzó a analizar las solicitudes individuales de la condición de refugiado mediante investigación y análisis especializados, ${ }^{8}$ tomando en cuenta las nuevas dimensiones y circunstancias que originan el desplazamiento forzoso de personas. De igual forma, la Comar, una vez

4 De acuerdo con la Organización Internacional para las Migraciones (OIM) se entiende por migración irregular aquel movimiento de personas del Estado de origen a otro con un fin laboral. La migración laboral está por lo general regulada en la legislación sobre migraciones de los Estados. Algunos países asumen un papel activo al regular la migración laboral externa y buscar oportunidades de trabajo para sus nacionales en el exterior. OIM, Términos clave de migración, http://www.iom.int/cms/es/sites/iom/home/about-migration/key-migration-terms-1. html\#Migraci\%C3\%B3n\%20irregular.

5 ACNUR, Oficina Regional para México y Centroamérica (en línea): http: / /www.cinu.org.mx/ onu/estructura/mexico/otr/acnur.htm.

6 Comisión Mexicana de Ayuda a Refugiados (Comar), La Creación de la COMAR, 27 de enero de 2011, http: / /www.comar.gob.mx/es/COMAR/La_creacion_de_la_COMAR.

7 La Convención de 1951 sobre el Estatuto de los Refugiados que fue adoptada el 28 de julio de 1951 en la ciudad de Ginebra en México fue aprobada por la Cámara de Senadores del Honorable Congreso de la Unión, el diecisiete de abril de dos mil, según decreto publicado en el Diario Oficial de la Federación del primero de junio del propio año.

8 Comar, La Nueva Tendencia, 27 de enero de 2011, http://www.comar.gob.mx/es/COMAR/ La_nueva_tendencia. 
Esta revista forma parte del acervo de la Biblioteca Jurídica Virtual del Instituto de Investigaciones Jurídicas de la UNAM

que reconocía la condición de refugiado, también tiene como atribución atender las necesidades prioritarias de los refugiados mediante esquemas de colaboración con otras dependencias, organismos internacionales, organizaciones de la sociedad civil e instituciones académicas. ${ }^{9}$

Finalmente, el 30 de octubre de 2014, después de una larga espera para contar con un ordenamiento jurídico especializado en el tema y que contemplara las principales prácticas y principios internaciones, se publicó en el Diario Oficial de la Federación la Ley Sobre Refugiados y Protección Complementaria y Asilo Político.

\section{MÉXICO Y LA MIGRACIÓN INTERNACIONAL}

Como mencionamos, las migraciones internacionales son un fenómeno común en la humanidad, pues el hombre emigra por numerosos factores, entre los que destacan los efectos de desastres naturales o económicos, la pobreza extrema, la aspiración humana de una vida mejor, por conflictos armados, por persecución política u otras violaciones a los derechos humanos, o por una mezcla de éstas.

Sin embargo, la razón más preocupante de las migraciones es cuando las personas lo hacen por persecución o cuando son amenazados directamente por un conflicto armado, u otras circunstancias graves que ponen en riesgo su vida, libertad o seguridad. Por lo tanto a diferencia del resto de los migrantes, las personas, que salen por las últimas razones señaladas, son quienes requieren protección internacional, ya que en caso de regresar a su país de origen se verían gravemente amenazados sus derechos humanos.

En el caso mexicano, este tema ha cobrado importancia debido a su privilegiada posición geográfica, al ser un país que comparte frontera con Estados Unidos, el cual sirve de paso para los diversos flujos migratorios y, además, quienes lo utilizan, muchas de las veces, pretenden llegar a este lugar como destino final. Al respecto y de acuerdo con el Instituto $\mathrm{Na}$ cional de Migración (INM), ${ }^{10}$ los nacionales de Guatemala, Honduras, El

9 Idem.

10 El Instituto Nacional de Migración es un órgano administrativo desconcentrado de la administración pública federal, dependiente de la Secretaría de Gobernación, el cual aplica 
Esta revista forma parte del acervo de la Biblioteca Jurídica Virtual del Instituto de Investigaciones Jurídicas de la UNAM

Salvador y Nicaragua constituyen entre 92 y $95 \%$ del total de las personas alojadas en estaciones migratorias, ${ }^{11}$ lo que representa la mayor parte de las migraciones de tránsito irregular por México hacia los Estados Unidos. No obstante, conocer el número exacto de migrantes en tránsito resulta ser una tarea difícil debido a la complejidad del asunto, ya que muchos de ellos prefieren hacerlo de manera clandestina ante el temor de ser identificados por las autoridades pertinentes debido a su condición jurídica irregular. Además, al estar relacionados con movimientos irregulares de personas a través de las fronteras, en estos flujos migratorios con mucha frecuencia las personas viajan ex profeso sin documentación alguna con la esperanza de dilatar y/o dificultar eventuales procesos de identificación con tal de llegar a destino su destino final. ${ }^{12}$ A pesar de ello, los diversos registros de las autoridades migratorias de México y Estados Unidos pueden dar un panorama cercano y aproximado del número de migrantes que pasan por esta ruta de manera irregular, la cual es sumamente numerosa, ya que se estima que cruzan alrededor de 500,000 personas cada año. ${ }^{13}$

\section{IDENTIFICACIÓN DE PERSONAS QUE REQUIEREN PROTECCIÓN INTERNACIONAL}

Debido a la posición geográfica en México, dentro de la migración, converge un fenómeno denominado flujo migratorio mixto, el cual consiste, una oleada de personas conformada por un grupo de migrantes por diversas causas y, además, personas que requieren protección internacional. Además, este fenómeno migratorio generalmente está relacionado con movi-

la legislación migratoria vigente. Su público usuario lo integra quienes nos visitan de otros países, y aquellos que quieren permanecer en México en forma temporal o permanente, así como los mexicanos que contratan extranjeros y quienes desean establecer vínculos familiares con un extranjero o extranjera.

11 Instituto Nacional de Migración (INM), Síntesis 2012: Estadística Migratoria, México, Centro de Estudios Migratorios, 2012, pp. 30-32.

12 Organización Internacional para las Migraciones (OIM), Migración irregular y flujos migratorios mixtos: enfoque de la OIM, MC/INF/297, p. 1.

13 INM, op. cit., pp. 30-33, y Homeland Security, 2012 Yearbook of Immigration Statistics, U.S. Office of Immigration Statistics, Washington, D.C., julio de 2013, pp. 92-115. 
Esta revista forma parte del acervo de la Biblioteca Jurídica Virtual del Instituto de Investigaciones Jurídicas de la UNAM

mientos irregulares, lo cual es un doble reto considerable para los Estados, no sólo porque violan su prerrogativa soberana de determinar qué ciudadanos, no nacionales, pueden entrar a su territorio y bajo qué condiciones, sino también porque las personas que participan en esos movimientos son muy propensas a haber sufrido privaciones, violaciones de derechos humanos y discriminación, y por lo tanto, son quienes requieren mayor asistencia individualizada y especial. ${ }^{14}$

Por eso la importancia de identificar con precisión si las personas huyen de sus países para proteger sus vidas o libertades, o bien, si lo hacen alentados para dejar atrás la pobreza u otras dificultades socioeconómicas, por lo que este hecho representa una tarea técnica ardua y que, hasta cierto punto, complica y/o retrasa el otorgar y garantizar protección internacional oportuna a quienes en verdad la necesitan. ${ }^{15}$

De tal forma que identificar a los solicitantes de asilo en los flujos migratorios mixtos que existen en México, representa un gran reto debido a la complejidad y variabilidad de estos mismos desplazamientos humanos.

Para reconocer este problema, México cuenta con dos leyes que reconocen la importancia de la identificación de las personas merecedoras de protección internacional: una es la Ley de Migración, y la otra, de particular interés para nuestra investigación, es la Ley sobre Refugiados y Protección Complementaria. La primera norma regula la movilidad internacional de personas en su sentido más amplio, la internación y estancia legal de extranjeros en el país, su tránsito y parte del fenómeno de emigración; ${ }^{16}$ mientras que la segunda norma regula las obligaciones internacionales contraídas por México en materia de protección humanitaria.

En lo que respecta a la Ley de Migración, ${ }^{17}$ se trata de un instrumento jurídico indispensable que reconoce jurídicamente la existencia de poblacio-

14 OIM, op. cit., p. 1.

15 Comité Ejecutivo del Programa del Alto Comisionado de Naciones Unidas para los Refugiados, Las migraciones mixtas y su relación con los éxodos de refugiados, incluyendo la repatriación de las personas que no requieren de protección internacional, así como la facilitación del retorno en su dimensión mundial, EC/48/SC/CRP.29, 25 de mayo de 2008, p. 3.

16 Cámara de Senadores de la República Mexicana, Exposición de Motivos, iniciativa con proyecto de decreto por el que se expide la Ley de Migración y se reforman, derogan y adicionan diversas disposiciones de la Ley General de Población, p. 1.

17 Artículo 3. Para efectos de la presente Ley se entenderá por: III. Asilado político: a quien solicita el ingreso a territorio nacional para proteger su libertad o su vida de persecu- 
Esta revista forma parte del acervo de la Biblioteca Jurídica Virtual del Instituto de Investigaciones Jurídicas de la UNAM

nes migrantes, entre ellos aquéllos que requieren protección internacional, siendo esto ya un gran avance porque se distingue la existencia de estos grupos en un universo de diferentes motivos de la migración y población extranjera en México.

Otra de las disposiciones relevantes de esta Ley de Migración,,$^{18}$ en materia de identificación, es que todos los migrantes tienen derecho a que se les dé información sobre el derecho a solicitar y recibir la condición de refugiado u otra protección alternativa, ya sea desde su ingreso a territorio mexicano o cuando se encuentren en estaciones migratorias.

Por otra parte, la Ley sobre Refugiados y Protección Complementaria, como mencionamos anteriormente, tiene como función regular la condición de refugiado y el otorgamiento de la protección complementaria, contempla asimismo disposiciones relativas al derecho de los migrantes a recibir información pertinente sobre el procedimiento para la identificación y otorgamiento de la condición de refugiado, la cual debe ser clara, oportuna y gratuita. A pesar que la ley ${ }^{19}$ no señala específicamente quién

ciones políticas, en los términos de los tratados y convenios internacionales de los cuales sea parte el Estado mexicano; IV. Apátrida: toda persona que no sea considerada como nacional por, ningún Estado, conforme a su legislación. La ley concederá igual trato a las personas que tienen una nacionalidad pero que no es efectiva. XXI. Protección complementaria: a la protección que la Secretaría otorga al extranjero que no ha sido reconocido como refugiado, consistente en no devolverlo al territorio de otro país en donde su vida se vería amenazada o se encontraría en peligro de ser sometido a tortura u otros tratos o penas crueles, inhumanos o degradantes; XXII. Refugiado: a todo extranjero que se encuentre en territorio nacional y que sea reconocido como refugiado por parte de las autoridades competentes, conforme a los tratados y convenios internacionales de que es parte el Estado Mexicano y a la legislación vigente;

18 Artículo 13. Los migrantes y sus familiares que se encuentren en el territorio de los Estados Unidos Mexicanos tendrán derecho a que se les proporcione información acerca de: III. La posibilidad de solicitar el reconocimiento de la condición de refugiado, del otorgamiento de protección complementaria o de la concesión de asilo político y la determinación de apátrida, así como los procedimientos respectivos para obtener dichas condiciones.

Artículo 109. Todo presentado, en su caso, tendrá los siguientes derechos desde su ingreso a la estación migratoria: II. Ser informado del motivo de su ingreso a la estación migratoria; del procedimiento migratorio; de su derecho a solicitar el reconocimiento de la condición de refugiado o la determinación de apátrida.

19 Ley sobre Refugiados y Protección Complementaria. Artículo 19. El solicitante tendrá derecho a recibir información clara, oportuna y gratuita sobre el procedimiento de reconocimiento de la condición de refugiado y sobre los derechos inherentes al mismo, así como los recursos que esta ley y otras le concedan. 
Esta revista forma parte del acervo de la Biblioteca Jurídica Virtual del Instituto de Investigaciones Jurídicas de la UNAM www.juridicas.unam.mx

es la autoridad encargada de proporcionar esta información, sin embargo en virtud del principio pro persona,${ }^{20}$ debería ser cualquier autoridad que tenga conocimiento de un posible caso de protección internacional y, por lo tanto, será aquel el obligado a dar aviso a la Comar para comenzar dicho procedimiento.

Sin embargo, a pesar de dicha obligación legal, existen reportes ${ }^{21}$ que señalan que son muy pocos los migrantes que son informados sobre este derecho, y quienes pudieran ejercer su derecho a solicitar asilo, debido a diversos factores, entre los que se encuentran el desconocimiento de la ley, la falta de sensibilidad de las autoridades, deficiente formación acerca de sus funciones, el abuso de autoridad y hasta el deseo de agilizar la deportación para no saturar las estaciones migratorias con solicitantes de asilo. Ante este panorama, la organización no gubernamental Sin Fronteras ${ }^{22}$ ha denunciado que la actual legislación sobre refugiados no es clara en cuanto a los mecanismos que debe implementar la autoridad para identificar posibles solicitantes de la condición de refugiado y, por tal razón, esta legislación no estaría garantizando materialmente el derecho a solicitar asilo en México. ${ }^{23}$ En este contexto, por lo tanto, se requiere la existencia de me-

20 El principio pro persona podría definido como: criterio fundamental que impone la naturaleza de los derechos humanos, la cual obliga a interpretar extensivamente las normas que los consagran o amplían y respectivamente las que los limitan o restringen. Conduce a la conclusión de que la exigibilidad inmediata e incondicional de los derechos humanos es la regla y su condicionamiento la excepción. Opinión separada del Juez Rodolfo E. Piza Escalante, en Corte Interamericana de Derechos Humanos, Exigibilidad del Derecho de rectificación o respuesta (artículos 14.1,1.1 y 2 Convención Americana sobre Derechos Humanos), Opinión Consultiva OC-7/86, serie A, núm. 7, 29 de agosto de 1986, párr. 36.

21 Monltavo, Tania L., "El Estado mexicano falla en dar refugio y desprotege a quienes lo reciben”, Animal Político, Nacional, 7 de abril de 2014.

22 Sin Fronteras es una organización civil creada en diciembre de 1995 por un grupo de activistas sociales y académicos, y su figura legal es la de Institución de Asistencia Privada (I.A.P.). Nuestro trabajo está basado en la convicción de que la migración es un fenómeno complejo y antiguo que debe ser abordado mediante políticas integrales y multidisciplinarias. Tenemos la convicción de que la sociedad civil debe jugar un papel fundamental en el tratamiento de la problemática migratoria: por un lado, ofreciendo servicios a las poblaciones migrantes y por otro lado, participando de manera activa en la creación de políticas y programas migratorios más adecuados. Sin Fronteras, ¿Quiénes somos?, http: / / www.sinfronteras.org.mx/ index.php/es/acerca-de/quienes-somos.

23 Sin Fronteras, Personas solicitantes de asilo y refugiados: la figura en México, México, Sin Fronteras, 2012, p. 19. 
Esta revista forma parte del acervo de la Biblioteca Jurídica Virtual del Instituto de Investigaciones Jurídicas de la UNAM

canismos concretos que cumplan con la ley de brindar información clara y oportuna para que las personas que se internan al país mediante los flujos migratorios mixtos conozcan sus derechos y puedan optar por ejercer el derecho a solicitar y recibir asilo sin limitación alguna, el cual no sólo está garantizado por la Constitución mexicana, ${ }^{24}$ sino también por otros instrumentos internacionales en los que México es parte. ${ }^{25}$

Por otro lado, la Corte Interamericana de Derechos Humanos (Corte IDH) en cuanto al derecho al asilo ha señalado que el establecimiento de procedimientos de identificación de necesidades de protección es una obligación positiva de los Estados y el no instituirlos constituiría una falta de debida diligencia. ${ }^{26}$ Por lo tanto, cualquier práctica por parte del Estado mexicano que entorpezca de manera significativa la etapa inicial de identificación estaría no sólo violando la ley interna sino también estaría incumpliendo con las normas internacionales sobre la materia, especialmente, con la Convención de 1951 sobre el Estatuto de los Refugiados y la Convención Americana de Derechos Humanos, ${ }^{27}$ por nombrar sólo algunos.

Sobre este último instrumento internacional, su artículo 1o. establece que los Estados parte se comprometen a respetar los derechos y libertades y a garantizar su libre y pleno ejercicio a toda persona sujeta a su jurisdicción, sin discriminación alguna. Por tal razón y complementando lo anterior, el artículo 22(7) señala que toda persona tiene derecho a buscar y recibir asilo de acuerdo con la ley interna y otros convenios internacionales. De esta manera, México estaría incumpliendo dichas obligaciones al

24 Artículo 11. Constitución Política de los Estados Unidos Mexicanos. En caso de persecución, por motivos de orden político, toda persona tiene derecho de solicitar asilo; por causas de carácter humanitario se recibirá refugio. La ley regulará sus procedencias y excepciones.

25 Artículo 14. Declaración Universal de Derechos Humanos. Artículo XXVII Declaración Americana de los Derechos y Deberes del Hombre. Artículo 22(7) Convención Americana sobre Derechos Humanos. Convención sobre el Estatuto de los Refugiados de 1951 y su Protocolo de 1967. Declaración de Cartagena de 1984.

26 Corte Interamericana de Derechos Humanos, Opinión Consultiva OC-21/14, Serie A, No. 21, Los derechos y garantías de las niñas y niños en el contexto de la migración y /o necesidad de protección internacional, 19 de agosto de 2014, párr. 82.

27 La Convención Americana de Derechos Humanos fue aprobada por la Honorable Cámara de Senadores del Congreso de la Unión, el día dieciocho del mes de diciembre del año de mil novecientos ochenta, según Decreto publicado en el Diario Oficial de la Federación del 9 de enero de 1981. 
Esta revista forma parte del acervo de la Biblioteca Jurídica Virtual del Instituto de Investigaciones Jurídicas de la UNAM

limitar la garantía y ejercicio de este derecho al no proporcionar información relevante a las personas necesitadas de protección internacional dentro de los flujos migratorios mixtos. Además, en ciertas poblaciones como los menores de edad, el Comité de los Derechos del Niño ha señalado que los Estados también se encuentran en la obligación de realizar una identificación temprana de niñas y niños que huyen por temor al reclutamiento forzoso, ya sea por las partes en un conflicto armado o por estructuras del crimen organizado, para así esclarecer si su caso amerita la solicitud de asilo o requiere protección complementaria. ${ }^{28}$

Por lo tanto, al existir una obligación del Estado de garantizar los derechos de la Convención, ${ }^{29}$ la Corte IDH ha establecido que puede ser cumplida de diferentes maneras en función del derecho específico que el Estado deba garantizar y de las particulares necesidades de protección, ${ }^{30}$ ya sea por su condición personal o por la situación específica en que se encuentre. ${ }^{31}$ Esta obligación implica el deber de los Estados de organizar todo el aparato gubernamental y, en general, todas las estructuras a través de las cuales se manifiesta el ejercicio del poder público, de manera tal que sean capaces de asegurar jurídicamente el libre y pleno ejercicio de los derechos humanos, ${ }^{32}$ incluyendo el derecho a solicitar asilo. Asimismo, la Corte IDH también ha señalado que dentro de las obligaciones de los Estados parte, de acuerdo con el artículo 2o., está el adoptar disposiciones de derecho

28 Comité de los Derechos del Niño, Observación General Num. 6:Trato de los menores no acompañados y separados de su familia fuera de su país de origen, párr. 54-63.

29 Convención Americana de Derechos Humanos. Artículo 22. Derecho de circulación y de Residencia. 7. Toda persona tiene el derecho de buscar y recibir asilo en territorio extranjero en caso de persecución por delitos políticos o comunes conexos con los políticos y de acuerdo con la legislación de cada Estado y los Convenios Internacionales.

30 Corte Interamericana de Derechos Humanos, Caso de la Masacre de Mapiripán vs. Colombia, sentencia de fondo, reparaciones y costas, 15 de septiembre de 2005, serie C, núm. 134, párr. 111 y 113, y Caso Gelmán vs. Uruguay, fondo y reparaciones, sentencia del 24 de febrero de 2011, serie C, núm. 221, párr. 76.

31 Corte Interamericana de Derechos Humanos, Caso de la Masacre de Pueblo Bello vs. Colombia, sentencia de fondo, reparaciones y costas, 31 de enero de 2006, serie C, núm. 140, párr. 111, y Corte Interamericana de Derechos Humanos, Caso Vera Vera y otra vs. Ecuador, sentencia de excepción preliminar, fondo, reparaciones y costas, 19 de mayo de 2011, serie C, núm. 224, párr. 42.

32 Corte Interamericana de Derechos Humanos, Caso Velásquez Rodríguez vs Honduras, serie C, núm. 4, 29 de julio de 1988, párr. 166, y Caso Gelmán, cit., párr. 189. 
Esta revista forma parte del acervo de la Biblioteca Jurídica Virtual del Instituto de Investigaciones Jurídicas de la UNAM

interno que también implica la expedición de normas y el desarrollo de prácticas conducentes a la efectiva observancia de dichas garantías. ${ }^{33}$

En ese sentido, el Estado tiene el deber de adoptar todas las medidas positivas para asegurar la plena vigencia de este derecho, por lo que resulta esencial implementar correctamente la ley y, por lo tanto, informar a todos los migrantes que se encuentran en México, incluyendo a potenciales refugiados, sobre el derecho a solicitar asilo y la posibilidad de acceder al procedimiento para determinar la condición de refugiado. No obstante, también resulta necesario informar sobre los trámites necesarios para ejercer este derecho y, en caso de estar interesados, se les deberá facilitar los medios necesarios y disponibles para ejercer plenamente este derecho. Consecuentemente, el Estado mexicano deberá permitir al solicitante permanecer en su territorio en espera de la decisión definitiva. ${ }^{34}$

Ahora bien, aun cuando se brindase a cabalidad información sobre este derecho a migrantes y refugiados, también es necesario fortalecer la identificación de estos últimos mediante capacitaciones a las autoridades para que cuenten con los elementos suficientes que les permita reconocer a potenciales refugiados en el flujo migratorio mixto. Esto es una práctica positiva que fortalece la implementación de la ley, debido a lo técnico y complejo que representa entender y conocer la definición de refugiado y sobre todo para las personas que escapan de persecución, en muchas de las ocasiones no se identifican como refugiados por diversos factores. Estos pueden por su perfil, su baja escolaridad, su situación socioeconómica, su grado de vulnerabilidad, por cuestiones de género, por razones culturales, por el idioma, por el trauma derivado de la persecución o por las ansias de querer llegar a un determinado destino, por el temor a sufrir abusos por parte de las autoridades, o bien, por combinarse más de una de ellas. Todas estas características influyen considerablemente en que posibles refugiados no se identifiquen como tal, y además, complica que sean reconocidos fácilmente por las autoridades y, por tal razón, la importancia que la autoridad tenga claro los elementos de la definición de la protección internacional.

33 Corte Interamericana de Derechos Humanos, Caso Mendoza y otros vs. Argentina, sentencia de excepciones preliminares, fondo y reparaciones, 14 de mayo de 2013, serie C, núm. 260, párr. 293.

34 ACNUR, Guía Práctica para los funcionarios del DAS: Recomendaciones de tratamiento ante solicitantes de la condición de refugiado, ACNUR, Colombia, p. 2. 
Esta revista forma parte del acervo de la Biblioteca Jurídica Virtual del Instituto de Investigaciones Jurídicas de la UNAM

Para entender este argumento basta poner un ejemplo muy común en México, es decir, el caso de un menor de edad de 10 años, que viaja no acompañado y quien ha decidido salir de su país de origen principalmente porque ha sido amenazado por pandillas de su barrio y, para evitar esta situación, se encamina hacia Estados Unidos porque tiene conocimiento que en ese país puede trabajar y ganar dinero. En primera instancia, se observa que se trata de un menor de edad, quien muy difícilmente entendería la información proporcionada acerca de los elementos para ser reconocido como un refugiado. En segundo lugar, debido a su escolaridad o la situación económica y social en la que se desarrolló en su país de origen podría influir en que el menor de edad no tome en cuenta la importancia que tiene recibir protección internacional en un país de tránsito. En tercer lugar, su deseo primordial de llegar a Estados Unidos sería confuso para la autoridad migratoria, quien podría considerar que el menor es un migrante económico y no un refugiado. En este contexto, el ACNUR ha reconocido este problema por lo que ha señalado que en varias ocasiones, detrás de las motivaciones económicas que alientan a las personas a dejar su país de origen pueden también ocultarse razones de orden racial, religiosas o políticas dirigidas contra un determinado grupo, lo que se equipara a la persecución. ${ }^{35}$

Además de conocer los elementos de la definición de refugiado por las autoridades también se requiere que éstas cuenten con información útil, necesaria y actualizada de las tendencias actuales de llegadas de refugiados individuales a México, en especial cuando en la actualidad los flujos masivos de refugiados han perdido fuerza, ${ }^{36}$ sobre todo del contexto latinoamericano, ${ }^{37}$ de donde se tienen registros que el mayor número de refugiados en México provienen de estos países. En este sentido, Juan Car-

35 ACNUR, Manual de Procedimientos y Criterios para Determinar La Condición de Refugiado en virtud de la Convención de 1951 y el Protocolo de 1967 sobre el Estatuto de los Refugiados, enero de 1992, HCR/IP/4/Spa/Rev.1. párr. 63.

36 De acuerdo con información del ACNUR, países como: Sudán del Sur, Mali, Siria, Somalia e Iraq son algunos de los países en donde mayor número de desplazamiento masivo se encuentran. La siguiente información puede consultarse en: http://www.acnur.org/t3/.

37 De acuerdo con las razones expresadas por los refugiados para haber solicitado el reconocimiento de la condición de refugiado en México se concentran en: violencia generalizada (38.6\%), opiniones políticas (24.5\%) y conflictos internos (21\%). Cobo, Salvador y Fuerte, Pilar, Refugiados en México: Perfiles sociodemográficos e integración social, México, Centro de Estudios Migratorios, 2012, p. 44. 
los Murillo González ${ }^{38}$ ha señalado que los desplazamientos forzados en la actualidad y en la región de América Latina ya no son generados por regímenes represivos, ya que en su mayoría obedecen al accionar de agentes no estatales quienes actúan al margen de la ley, o bien por redes transnacionales del crimen organizado e incluso individuos particulares, frente a quienes la protección nacional de los Estados resulta ineficaz o inexistente. De esta manera se explicaría el que, actualmente, el desplazamiento forzado de personas se dé tanto dentro del marco de un conflicto armado interno, en situaciones de violencia generalizada o violaciones masivas de derechos humanos, tanto como en situaciones de paz bajo regímenes democráticos, libremente electos. ${ }^{39}$

En consecuencia y tomando en cuenta todos los elementos mencionados se requiere fortalecer la correcta implementación de Ley de Migración y Ley sobre Refugiados para identificar y consecutivamente canalizar a posibles personas sujetas a protección internacional dentro del contexto de los movimientos migratorios mixtos.

\section{DERECHO AL ACCESO AL PROCEDIMIENTO PARA SOLICITAR ASILO}

Otro de los retos para una correcta implementación de la Ley sobre los Refugiados en México es que los potenciales solicitantes, incluyendo aquellos identificados, puedan acceder, sin limitación alguna, al procedimiento de reconocimiento de su condición de refugiado. Esto debido a que la aplicación de la Convención de 1951, del Protocolo de 1967 y otros instrumentos internacionales exige mejorar tales procedimientos, haciéndolos justos, eficientes y accesibles..$^{40}$ De tal forma que el debido proceso juega un rol importante en este tema, sobre todo cuando éste es uno de los pilares del derecho internacional de los derechos humanos y del derecho

38 Asesor Jurídico Regional, Alto Comisionado de las Naciones Unidas para los Refugiados (ACNUR), Costa Rica.

39 ACNUR, Presentación del ACNUR en el XXXIII Curso de derecho internacional - La protección internacional de los refugiados en las Américas, 17 Agosto 2006, p. 2.

40 Mondelli, Juan Ignacio, Procedimientos de asilo justos y eficientes: estándares mínimos del derecho internacional de los derechos humanos y del derecho internacional de refugiados, Buenos Aires, ACNUR, 2005, p. 4. 
Esta revista forma parte del acervo de la Biblioteca Jurídica Virtual del Instituto de Investigaciones Jurídicas de la UNAM www.juridicas.unam. $\mathrm{mx}$

constitucional mexicano. Al respecto, este principio apunta a que la obligación de los Estados no es sólo negativa, es decir, consistir en no impedir el acceso al debido proceso; sino que fundamentalmente se trata de un deber positivo, ya que el Estado tiene que organizar su aparato institucional de modo que todos los individuos puedan acceder a esos recursos..$^{41}$ Desde esta perspectiva, no basta con que constitucionalmente se garantice a todas las personas, sin distinción alguna, el derecho al debido proceso, ${ }^{42}$ sino también se requiere tomar medidas apropiadas y específicas para que éste se materialice, y por lo tanto, sea accesible a todos, independientemente de su situación migratoria. Al respecto, la Corte IDH ha señalado que las garantías de debido proceso se aplican a cualquier persona independiente de su edad y condición de estancia en un país. En esta línea, la Corte IDH, también, ha precisado que el debido proceso legal es un derecho que debe ser garantizado a toda persona, independientemente de su estatus migratorio. ${ }^{43}$ Esto implica que el Estado debe garantizar que toda persona extranjera, aun cuando fuere un migrante en situación irregular, tenga la posibilidad de hacer valer sus derechos y defender sus intereses en forma efectiva y en condiciones de igualdad procesal con otros justiciables. ${ }^{44}$ También, la Corte IDH ha señalado que integra la obligación el otorgamiento al solicitante de asilo de las facilidades necesarias, ${ }^{45}$ incluyendo los servicios de un intérprete competente, el acceso a asesoría y representación legal,

41 Comisión Interamericana de Derechos Humanos (CIDH), El acceso a la justicia como garantía de los derechos económicos, sociales y culturales. Estudio de los estándares fijados por el sistema Interamericano de derechos humanos, 7 Septiembre 2007, OEA/Ser. L/V/II.129, párr. 1.

42 Constitución Política de los Estados Unidos Mexicanos. Artículo 16. Nadie puede ser molestado en su persona, familia, domicilio, papeles o posesiones, sino en virtud de mandamiento escrito de la autoridad competente, que funde y motive la causa legal del procedimiento.

43 Corte Interamericana de Derechos Humanos, Opinión Consultiva, OC-18/13, Condición Jurídica y Derechos de los Migrantes Indocumentados, 17 de septiembre de 2003, serie A, núm. 18, párr. 121-122, y Corte Interamericana de Derechos Humanos, Caso Vélez Loor vs. Panamá, sentencia de excepciones preliminares, fondo, reparaciones y costas, 23 de noviembre de 2010, párr. 143.

44 Caso Vélez Loor vs. Panamá, cit., párr. 143.

45 Corte Interamericana de Derechos Humanos, Caso Familia Pacheco Tineo vs. Bolivia, sentencia de excepciones preliminares, fondo, reparaciones y costas, 25 de noviembre de 2013, serie C, núm. 272, párr. 159. 
Esta revista forma parte del acervo de la Biblioteca Jurídica Virtual del Instituto de Investigaciones Jurídicas de la UNAM

así como someter su solicitud ante las autoridades como durante el trámite de la misma. ${ }^{46}$

De esta manera garantizar el derecho al debido proceso incluye que las personas que requieren protección internacional tengan acceso al procedimiento de asilo sin estar limitadas por aquellas prácticas o conductas lesivas que obstaculizan el ejercicio pleno de este derecho. Sobre todo cuando se ha señalado que existen prácticas contrarias a la figura del asilo regulada en la Convención de 1951 sobre el Estatuto de los Refugiados. ${ }^{47}$

En el caso de refugiados podemos observar disposiciones jurídicas específicas, que legalmente se ajustan a las obligaciones internacionales, como en el caso de la Ley de Migración que, en su artículo 11, señala que independientemente de la situación migratoria, los migrantes tienen derecho al debido proceso. ${ }^{48}$ Dicha norma también se aplica e incluye a los refugiados y otras personas que requieren protección internacional, con independencia de su estancia regular o irregular en el país. Paralelamente y fortaleciendo este derecho, el artículo 11 de la Ley sobre Refugiados y Protección Complementaria, ${ }^{49}$ garantiza específicamente el derecho a solicitar asilo.

46 Idem.

47 Sin Fronteras, Ser migrante no me hace delincuente: situación de las personas en detención en las estaciones migratorias de Iztapalapa, Distrito Federal, Tenosique y Villahermosa, Tabasco, México, 2013, pp. 90 y 91.

48 Una de las interpretaciones sobre lo que debe de entenderse por debido proceso, el Comité de Derechos Humanos de la ONU ha señalado que el derecho a un recurso efectivo no debe interpretarse necesariamente en el sentido de que exige siempre un recurso judicial. Los recursos administrativos en muchos casos son adecuados, y quienes viven bajo la jurisdicción de un Estado Parte tienen la expectativa legítima de que, sobre la base del principio de buena fe, todas las autoridades administrativas, al adoptar decisiones, tendrán en cuenta las disposiciones del Pacto. Esos recursos administrativos deben ser accesibles, no onerosos, rápidos y eficaces. También es conveniente muchas veces establecer un derecho último de apelación judicial con respecto a los procedimientos administrativos de este tipo. Naciones Unidas, Recopilación de las observaciones generales y recomendaciones generales adoptadas por órganos creados en virtud de tratados de derechos humanos, OG9, HRI/GEN/1/Rev.9 (vol. I), 27 de mayo de 2008, p. 63.

49 Artículo 11. Todo extranjero que se encuentre en territorio nacional tiene derecho a solicitar, por sí, por su representante legal o por interpósita persona, el reconocimiento de la condición de refugiado. Si el extranjero solicitase dicho reconocimiento a través de su representante legal o por interpósita persona, deberá de ratificar su solicitud ante la Secretaría dentro del término de tres días hábiles. Si el extranjero la ratifica se continuará el procedimiento de reconocimiento, en caso contrario, se tendrá por no presentada la solicitud. El procedimiento de reconocimiento de la condición de refugiado sólo podrá continuarse por 
Esta revista forma parte del acervo de la Biblioteca Jurídica Virtual del Instituto de Investigaciones Jurídicas de la UNAM

Complementando lo anterior, el artículo $18^{50}$ establece ciertos lineamientos específicos y relevantes sobre el inicio para ejercer este derecho, el cual señala que la persona tiene un plazo de 30 días hábiles contados a partir del día siguiente al ingresar a territorio mexicano para solicitar la condición de refugiado, siendo una de las disposiciones más controvertidas al acceso al procedimiento, ya que la Convención sobre el Estatuto de los Refugiados de 1951 no establece en su texto disposición alguna sobre el plazo requerido para presentar una solicitud de asilo. Al contrario, las medidas de tiempo son establecidas por la legislación interna de cada Estado parte, una vez que han adoptado este instrumento internacional en su derecho interno.

Sobre este asunto, la organización Sin Fronteras, ha señalado que una de las problemáticas del acceso al procedimiento de asilo es el establecimiento de plazos cortos para solicitar el reconocimiento de este derecho, y por lo tanto, esta disposición en la Ley sobre Refugiados, en muchos de los casos, deja afuera a gente que es merecedora a protección internacional. ${ }^{51}$ Sobre este asunto, la Oficina de Naciones Unidas para los Refugiados ha considerado como buena práctica en los procedimientos de asilo simplemente no establecer plazo alguno, debido a que éste implica un arbitrario límite temporal para que el solicitante ejerza su derecho a solicitar y recibir asilo. ${ }^{52}$ Así las cosas, el procedimiento debería garantizar estándares mínimos

el solicitante o por su representante legal de conformidad con lo establecido en esta ley y su reglamento.

50 Artículo 18. El extranjero que solicite ser reconocido como refugiado deberá presentar por escrito su solicitud ante la Secretaría dentro del término de 30 días hábiles contados a partir del día hábil siguiente al que haya ingresado al país o, en su caso, a aquél en que le haya sido materialmente posible presentarla en los términos que defina el reglamento. En el supuesto previsto en el artículo 13, fracción III, el plazo para presentar la solicitud correrá a partir del día siguiente al que tenga conocimiento de los hechos a los que alude dicha disposición. En el caso en que al solicitante no le sea posible presentar la solicitud por escrito, la presentará verbalmente, debiéndose asentar en un acta las manifestaciones del solicitante. Si el extranjero no tiene posibilidad de comunicarse verbalmente, se tomarán las medidas necesarias para asentar en el acta correspondiente las manifestaciones del solicitante. En el supuesto de que el extranjero no comprenda el idioma español, se procederá conforme a lo establecido por el último párrafo del artículo 23 de esta ley. El procedimiento para el reconocimiento de la condición de refugiado será gratuito.

51 Manu Ureste, "Estas son las principales trabas que México pone a los migrantes que buscan refugio en el país”, Animal Político, Nacional, 31 de octubre de 2014, p. 1

52 Unidad Legal Regional del ACNUR, Protección de Refugiados en América Latina: Buenas Prácticas Legislativas, http://www.acnur.org/t3/?id=1400. 
Esta revista forma parte del acervo de la Biblioteca Jurídica Virtual del Instituto de Investigaciones Jurídicas de la UNAM

y que son precisamente los que establecen los principales instrumentos internacionales en la materia.

Además, tomando en cuenta la naturaleza y espíritu de la Convención sobre el Estatuto de los Refugiados de 1951, intrínsecamente humanitarios y alineados para proteger la figura del asilo, la solicitud para reconocer esta condición no debería estar limitada o impedida por un plazo,,$^{53}$ pues de otra forma se estaría menoscabando el sentido intrínseco de esta figura. Inclusive, podría afirmarse que tener un tiempo de vigencia para ejercer este derecho no se contradice con el efecto declarativo que emana de la condición una vez otorgado, ya que una persona es refugiada por lo que ha vivido y no por el hecho de que se le reconozca como tal, por lo que la postura mexicana en el fondo estaría limitando indebidamente esta institución, tal como lo establece la Convención de 1951 sobre el Estatuto de los Refugiados.

Para complementar lo anterior y tomando en cuenta el señalamiento de la organización Sin Fronteras, podemos mencionar algunos ejemplos que por diversas razones un potencial refugiado podría no ejercer este derecho en la oportunidad establecida por la ley, ya que podrían existir razones o impedimentos ajenos a su voluntad. Algunos de ellos podrían ser cuando el solicitante, al llegar a territorio mexicano, desconociere el plazo para ejercer aquel derecho o simplemente desconociere la autoridad a quien debería dirigirse y quien es la encargada de determinar la condición de refugiado, o incluso, la persona podría hallarse privado de su libertad durante su estancia en territorio mexicano y esto le impidiere solicitar la protección internacional. Para atender algunos de estos casos, el Reglamento ${ }^{54}$ de la Ley sobre Refugiados y Protección Complementaria resolvió que el plazo original de 30 días podrá extenderse, sólo de manera excepcional, cuando el extranjero acredite las causas ajenas a su voluntad por las que no

53 Es el término o espacio de tiempo que se le concede a las partes para responder o probar lo expuesto y negado en juicio. Puede ser legal, judicial y convencional: se llama legal el concedido por la ley, estatuto, estilo o costumbre sin ministerio del juez ni de los litigantes... Joaquín Escriche, Diccionario Razonado de Legislación y Jurisprudencia, Madrid, Librería de Rosa, Bouret y C, 1851, p. 1351.

54 Reglamento de la Ley sobre Refugiados y Protección Complementaria. Artículo 19. Para efectos del cumplimiento del artículo 18 de la ley, la Coordinación de manera excepcional dará trámite a las solicitudes presentadas fuera del plazo previsto, cuando el extranjero acredite que por causas ajenas a su voluntad no le fue materialmente posible presentarla oportunamente. 
Esta revista forma parte del acervo de la Biblioteca Jurídica Virtual del Instituto de Investigaciones Jurídicas de la UNAM

le fue posible presentar la solicitud oportunamente. Sin embargo, desde nuestro punto de vista, esta disposición resulta ser sumamente discrecional, ya que depende de la autoridad administrativa determinar si son razonables o no los motivos o argumentos presentados por el solicitante que le impidieron presentar su solicitud a tiempo. Además, en ciertos casos y en estricto sentido resulta sumamente complejo comprobar o acreditar los hechos que prohibieron hacerlo en tiempo. Algunos ejemplos de ello son comprobar que la persona efectivamente desconocía la existencia del plazo o la existencia y ubicación de la autoridad encargada, o bien, acreditar que fue impedido de hacerlo tras haber sido privado de su libertad. Desde esta perspectiva, el artículo 19 del Reglamento de la Ley de Refugiados no estaría cumpliendo cabalmente con el verdadero sentido y fin de la Convención de 1951 y sobre todo con el sentido humanitario ni los efectos declarativos de esta figura.

Por lo anterior, esta disposición de la Ley sobre Refugiados menoscaba el sentido real de la Convención de 1951 sobre el Estatuto de los Refugiados, y por lo tanto, impide cabalmente el acceso al procedimiento de asilo.

\section{ACCESO AL TERRITORIO A PERSONAS NECESITADAS \\ DE PROTECCIÓN INTERNACIONAL}

Otro de los graves obstáculos para acceder al procedimiento de asilo y que es en detrimento al debido proceso es cuando a la persona se le impide acceder siquiera al territorio en el cual podría requerir protección internacional. Sobre este asunto, la Convención sobre el Estatuto de los Refugiados de $1951^{55}$ señala que ningún Estado parte podrá, por expulsión o devolución, poner en modo alguno a un refugiado en las fronteras de los territorios en donde corre riesgo de ser perseguido. Siendo éstos algunos de los principios fundamentales del derecho internacional de los refugiados.

La Ley sobre Refugiados y Protección Complementaria, para reforzar los derechos mencionados: a la no devolución y a la prohibición de rechazo

55 Artículo 33. Prohibición de expulsión y de devolución (refoulement) 1. Ningún Estado Contratante podrá, por expulsión o devolución, poner en modo alguno a un refugiado en las fronteras de los territorios donde su vida o su libertad peligre por causa de su raza, religión, nacionalidad, pertenencia a determinado grupo social, o de sus opiniones políticas. 
Esta revista forma parte del acervo de la Biblioteca Jurídica Virtual del Instituto de Investigaciones Jurídicas de la UNAM

en frontera, señala en su artículo 6o. que ningún solicitante o refugiado podrá en modo alguno ser rechazado en frontera o devuelto de cualquier forma al territorio de otro país donde su vida peligre, conforme a la definición legal de refugiado.

De igual forma para proteger a otras personas que merecen protección internacional y estar acorde con otros tratados internacionales, ${ }^{56}$ este artículo añadió la prohibición de rechazar o devolver a una persona cuando existan razones fundadas para considerar que estaría en peligro de ser sometido a tortura u otros tratos o penas crueles, inhumanas o degradantes, ${ }^{57}$ por lo que representa un gran avance legislativo.

A tal efecto, estas disposiciones contemplan la necesidad de admitir a los solicitantes de asilo, refugiados y otras personas merecedoras de protección internacional a México, ya que su rechazo en las fronteras sin que se haya garantizado el acceso al procedimiento haría incurrir al Estado en severa responsabilidad nacional e internacional, al contravenir algunos de los pilares del derecho internacional de los refugiados. Al respecto, el Comité Ejecutivo del ACNUR, ${ }^{58}$ del cual México es parte, señaló que con la

56 La Convención contra la Tortura y otros Tratos o Penas Crueles, Inhumanos o Degradantes fue aprobada por la Cámara de Senadores del H. Congreso de la Unión, el día nueve del mes de diciembre del año de mil novecientos ochenta y cinco, según Decreto publicado en el Diario Oficial de la Federación del día diecisiete del mes de enero del año de mil novecientos ochenta y seis.

57 Convención contra la Tortura y otros Tratos o Penas Crueles, Inhumanos o Degradantes. Artículo 3. 1. Ningún Estado Parte procederá a la expulsión, devolución o extradición de una persona a otro Estado cuando haya razones fundadas para creer que estaría en peligro de ser sometida a tortura.

2. A los efectos de determinar si existen esas razones, las autoridades competentes tendrán en cuenta todas las consideraciones pertinentes, inclusive, cuando proceda, la existencia en el Estado de que se trate de un cuadro persistente de violaciones manifiestas, patentes o masivas de los derechos humanos.

58 El Comité Ejecutivo del Alto Comisionado de Naciones Unidas para los Refugiados (EXCOM) es el órgano subsidiario de la Asamblea General que entró en funciones el 1o de enero de 1959. Actualmente está compuesto por 87 Estados miembros, el Comité Ejecutivo se reúne anualmente en Ginebra para examinar y aprobar los programas y el presupuesto del ACNUR, asesora sobre la protección internacional y analiza una amplia gama de otras cuestiones con el ACNUR y sus socios intergubernamentales y no gubernamentales. El Comité Permanente del Comité Ejecutivo se reúne varias veces al año para continuar el trabajo del Comité entre sesiones plenarias.

ACNUR, Comité Ejecutivo del ACNUR (EXCOM), http: / / www.acnur.org/t3/el-acnur/excom/. 
Esta revista forma parte del acervo de la Biblioteca Jurídica Virtual del Instituto de Investigaciones Jurídicas de la UNAM

finalidad de proteger la institución del asilo, los Estados deberán admitir a personas necesitadas de protección para que accedan al procedimiento que determinen el estatuto y las necesidades de protección. ${ }^{59}$ Esto incluye a las personas en cualquier punto de internación, sea en los aeropuertos, puertos marítimos o fluviales, o por tierra, sin importar si lo hizo de manera regular o irregular.

Esta decisión arranca de las diferentes dificultades que han enfrentado los migrantes en el mundo para presentar solicitudes de asilo en la frontera o en los aeropuertos ya que, en múltiples ocasiones, son retenidos e impedidos de ingresar formalmente al territorio del país de asilo. En tal sentido, esta práctica es especialmente preocupante cuando, por ejemplo, los funcionarios en puestos fronterizos tienen amplias facultades y, además, no cuentan con el conocimiento técnico y suficiente en materia de asilo. ${ }^{60} \mathrm{De}$ aquí la importancia de poner mayor énfasis en campañas de capacitación y sensibilización dirigidas, principal y aunque no únicamente, a los oficiales de migración y a otras autoridades con injerencia en el tema para inhibir que incurran en estas prácticas lesivas a los principios rectores del derecho internacional de los refugiados.

Otro de los factores que actualmente restringen el acceso al territorio a posibles solicitantes de asilo, son las políticas de Estado basadas en el argumento de brindar mayor seguridad en las fronteras. A pesar que es una facultad exclusiva de los Estados la seguridad nacional, en muchos de los casos, ocurre que esta práctica menoscaba los principios de la institución del asilo, sobre todo cuando se niega el acceso al procedimiento a potenciales refugiados, por no poder siquiera entrar al territorio, o bien, en ciertos casos, se les ha expulsado de los países sin brindarles la oportunidad de ejercer el derecho a solicitar y recibir asilo. ${ }^{61}$ En el caso mexicano esta política se ha estado implementando en los últimos años a raíz de la constante presión de Estados Unidos de América, su país vecino del norte y que, en reiteradas ocasiones, ha solicitado a México mayor seguridad y control en su frontera sur, la cual es considerada de fácil acceso. Mayores y más conti-

59 Comité Ejecutivo, No 82 (XLVIII) Conclusión sobre la Salvaguardia de la Institución del Asilo, 1997, 48o. periodo de sesiones del Comité Ejecutivo.

60 Mondelli, op. cit., p. 16.

61 ACNUR, Protección de los refugiados: Guía sobre el derecho internacional de los refugiados, ACNUR, 1 Diciembre 2001, p. 6. 
Esta revista forma parte del acervo de la Biblioteca Jurídica Virtual del Instituto de Investigaciones Jurídicas de la UNAM

núas medidas restrictivas como ésta, a su juicio, redundarían en una menor migración hacia Estados Unidos de personas provenientes, sobre todo, de Centroamérica. Sin embargo, como lo hemos mencionado, estas medidas lesionan la institución del asilo, ya que en efecto, no sólo contravienen las obligaciones estipuladas en la Convención de 1951 y la Declaración de Cartagena; sino que también vulneran los compromisos adoptados en el Plan México, es decir, mantener la política de fronteras abiertas para garantizar la protección y seguridad de quienes tienen derecho a protección internacional. ${ }^{62}$

Aunado a lo anterior y sin necesidad de comprometer su seguridad, México debería continuar fortaleciendo su tradición de asilo y brindar protección internacional, mediante la implementación de buenas prácticas que permitan identificar a quien justificadamente lo necesita. En este sentido, la Corte IDH ha señalado que el contenido del principio de no devolución reconoce un ámbito de aplicación personal y material particular, y obligaciones correlativas específicas, las que deben de entenderse como de naturaleza complementaria, en términos de la Convención y el principio pro persona. Ello implica, en definitiva, efectuar la interpretación más favorable para el efectivo goce y ejercicio de los derechos y libertades fundamentales, aplicando aquella norma que otorgue mayor protección al ser humano. ${ }^{63}$

Por lo tanto, no basta con que la ley mexicana contemple esta obligación y ésta se adecúe a los tratados internacionales, sino también, se requiere la formulación de políticas migratorias coherentes con el derecho internacional de los refugiados para una correcta implementación de la ley, además de fortalecer a los agentes de migración sobre los principios pilares de este derecho. Sobre todo cuando se ha denunciado que el sistema mexicano de ingreso y protección, evidencia graves falencias que impiden el acceso a este procedimiento a potenciales refugiados. ${ }^{64}$

62 Declaración y Plan de Acción México: Para fortalecer la protección internacional de los refugiados en América Latina, Ciudad de México, 16 de noviembre de 2004, p. 2.

63 Opinión Consultiva OC-21/14, cit., párr. 234.

64 Discurso de Audiencia temática "Situación de derechos humanos de los refugiados y solicitantes de asilo en las Américas en el 30o. aniversario de la Declaración de Cartagena”, 153o. periodo de sesiones, 27 de octubre de 2014. 


\section{CONCLUSIÓN}

En lo que al derecho internacional de los refugiados compete, en el caso mexicano, la adopción de medidas legislativas no es el problema principal, ya que actualmente cuenta con un marco regulatorio que cumple con los estándares internacionales mínimos del área. Sin embargo, la implementación de la ley mexicana, al igual de los instrumentos internacionales en la materia, adolecen de problemas que, desde nuestro punto de vista, requieren mayor énfasis en soluciones prácticas en la identificación, admisión al territorio y acceso al procedimiento de asilo. En consecuencia, no sólo se requiere reforzar y hacer más eficientes los mecanismos existentes, sino también encontrar mejores e innovadoras prácticas que fortalezcan la institución del asilo y que ayuden a la implementación de la ley actual.

En el caso de la identificación de posibles solicitantes de asilo, se requiere contar con mecanismos de información a todos los migrantes que transitan por México, así como robustecer el sistema de capacitación de los funcionarios públicos relacionados al tema para que cuenten con conocimientos y herramientas apropiadas de individualización y canalización de solicitantes dentro de un complejo flujo migratorio mixto.

Sobre el acceso al procedimiento de asilo, México debería ajustarse a las mejores prácticas internacionales en la materia, las cuales señalan que éste debe ser justo y eficiente en el manejo de las solicitudes de asilo, eliminando aquéllos obstáculos que limitan el derecho al debido proceso como fijar un plazo para el ejercicio de éste u otras medidas.

En lo que respecta a la admisibilidad de refugiados se debería privilegiar el sentido humanitario de la institución del asilo y, en consecuencia, no limitarla por dudosas razones de seguridad que, en muchos de los casos, no se avienen con el verdadero sentido de la norma internacional, ya que México podría cumplir con su obligación internacional en el área de refugiados sin comprometer el tema de seguridad, y para ello, requeriría de una nueva formulación de interpretación de la ley, la cual debe ser apropiada a la protección internacional y que implemente correctamente el sentido de la misma.

Todo lo anterior tiene una sola finalidad, no sólo ajustar la ley nacional con obligaciones internacionales; sino también mantener y fortalecer la tradición humanitaria del asilo en México mediante una correcta imple- 
Esta revista forma parte del acervo de la Biblioteca Jurídica Virtual del Instituto de Investigaciones Jurídicas de la UNAM

mentación de ambas normas jurídicas con los mejores estándares internacionales.

\section{BIBLIOGRAFÍA}

ACNUR, ACNUR un instrumento de Paz, Editorial Artegraf, Madrid, 1996. -, Creación del ACNUR, http://www.acnur.org/t3/el-acnur/historiadel-acnur/acnur-como-honrar-un-mandato/.

- Comité Ejecutivo del ACNUR (EXCOM), http: / / www.acnur.org/t3/elacnur/excom/.

- Guía Práctica para los funcionarios del DAS: Recomendaciones de tratamiento ante solicitantes de la condición de refugiado, ACNUR, Colombia. - Manual de Procedimientos y Criterios para Determinar La Condición de Refugiado en virtud de la Convención de 1951 y el Protocolo de 1967 sobre el Estatuto de los Refugiados, enero de 1992, HCR/IP/4/Spa/Rev.1.

—, Oficina Regional para México y Centroamérica, http://www.cinu.org. $\mathrm{mx} /$ onu / estructura / mexico/otr / acnur. htm.

- Protección de los refugiados: Guía sobre el derecho internacional de los refugiados, ACNUR, 1 diciembre 2001.

—, ¿Quiénes somos ?, http://www.acnur.org/index.php?id_pag=24.

$\mathrm{BBC}$, "El mundo tiene hoy más refugiados que en la Segunda Guerra Mundial", BBC Mundo, 20 de junio de 2014.

CoBo, Salvador y Fuerte, Pilar, Refugiados en México: perfiles sociodemográficos e integración social, México, Centro de Estudios Migratorios, 2012. Comité Internacional de la Cruz Roja (CICR), Fundación de la Federación de Sociedades Nacionales de la Cruz Roja y la Media Luna Roja, 2 de febrero de 2007, http: / / www.icrc.org/spa/resources/documents/misc/6y2p85.htm.

Comisión Mexicana de Ayuda a Refugiados (Comar), La Creación de la COMAR, 27 de enero de 2011, http://www.comar.gob.mx/es/COMAR/La_crea cion_de_la_COMAR.

-, La nueva tendencia, 27 de enero de 2011, http:/ /www.comar.gob.mx/ es/COMAR/La_nueva_tendencia.

Comité Ejecutivo del Programa del Alto Comisionado de Naciones Unidas para los Refugiados, Las migraciones mixtas y su relación con los éxodos de refugiados, incluyendo la repatriación de las personas que no requieren de protec- 
Esta revista forma parte del acervo de la Biblioteca Jurídica Virtual del Instituto de Investigaciones Jurídicas de la UNAM

ción internacional, así como la facilitación del retorno en su dimensión mundial, EC/48/SC/CRP.29, 25 de mayo de 2008.

Comité Ejecutivo, No 82 (XLVIII) Conclusión sobre la Salvaguardia de la Institución del Asilo, 1997, 48o. periodo de sesiones del Comité Ejecutivo.

Comisión Interamericana de Derechos Humanos (CIDH), El acceso a la justicia como garantía de los derechos económicos, sociales y culturales. Estudio de los estándares fijados por el sistema Interamericano de derechos humanos, 7 Septiembre 2007, OEA/Ser. L/V/II.129.

Discurso de Audiencia temática, Situación de derechos humanos de los refugiados y solicitantes de asilo en las Américas en el 30o. aniversario de la Declaración de Cartagena, 153o. periodo de sesiones 27 de octubre de 2014

ESCRICHE, Joaquín, Diccionario Razonado de Legislación y Jurisprudencia, Madrid, Librería de Rosa, Bouret y C, 1851.

Homeland Security, 2012 Yearbook of Immigration Statistics, Washington, D.C., U.S. Office of Immigration Statistics, 2013.

InstiTuto Nacional de Migración, Síntesis 2012: estadística migratoria, México, Centro de Estudios Migratorios, 2012.

Mager Hois, Elisabeth A., Kikapú:Pueblos Indígenas del México contemporáneo, México, Comisión Nacional para el Desarrollo de los Pueblos Indígenas.

Mondelli, Juan Ignacio, Procedimientos de asilos justos y eficientes: estándares mínimos del derecho internacional de los derechos humanos y del derecho internacional de refugiados, Buenos Aires, ACNUR, 2005.

Montalvo, Tania L., "El Estado mexicano falla en dar refugio y desprotege a quienes lo reciben”, Animal Político, Nacional, 7 de abril de 2014.

Murillo GonZÁleZ, Juan Carlos, Presentación del ACNUR en el XXXIII Curso de derecho internacional - La protección internacional de los refugiados en las Américas, 17 de agosto de 2006.

NACIONES Unidas, Recopilación de las observaciones generales y recomendaciones generales adoptadas por órganos creados en virtud de tratados de derechos humanos, OG9, HRI/GEN/1 / Rev.9 (vol. I), 27 de mayo de 2008.

Organización Mundial para las Migraciones (OIM), Términos clave de migración, http://www.iom.int/cms/es/sites/iom/home/about-migration/keymigration-terms-1.html\#Migraci\%C3\%B3n\%20irregular.

OIM, Migración irregular y flujos migratorios mixtos: enfoque de la OIM, MC/ INF/297.

Sin Fronteras, ¿Quiénes somos?, http: / / www.sinfronteras.org.mx/index.php/ es/acerca-de/ quienes-somos. 
Esta revista forma parte del acervo de la Biblioteca Jurídica Virtual del Instituto de Investigaciones Jurídicas de la UNAM

, Personas solicitantes de asilo y refugiados: la figura en México, Sin Fronteras, México, 2012, http: / / www.cidh.org/countryrep/accesodesc07sp/Acce sodesci-ii.sp.htm.

, Ser migrante no me hace delincuente: situación de las personas en detención en las estaciones migratorias de Iztapalapa, Distrito Federal, Tenosique y Villahermosa, Tabasco, México, 2013

Unidad Legal Regional del ACNUR, Protección de Refugiados en América Latina: Buenas Prácticas Legislativas, http: / / www.acnur.org/t3 /?id=1400.

UReste, Manu, "Estas son las principales trabas que México pone a los migrantes que buscan refugio en el país”, Animal Político, 31 de octubre de 2013.

WiLKINSON, Ray, El asilo no tiene precio, vale tanto como la propia vida, http: / / www.acnur.org/t3/el-acnur/historia-del-acnur/el-asilo-no-tiene-precio-valetanto-como-la-propia-vida/.

Legislación nacional e internacional y jurisprudencia

Constitución Política de los Estados Unidos Mexicanos de 1917.

Ley de Migración.

Ley sobre Refugiados y Protección Complementaria.

Reglamento de la Ley de Refugiados y Protección Complementaria.

Declaración Universal de Derechos Humanos.

Declaración Americana de los Derechos y Deberes del Hombre.

Convención Americana sobre Derechos Humanos.

Convención contra la Tortura y otros Tratos o Penas Crueles, Inhumanos o Degradantes.

Convención sobre el Estatuto de los Refugiados de 1951 y su Protocolo de 1967.

Declaración de Cartagena de 1984.

Plan de Acción México.

Cámara de Senadores de la República Mexicana, Exposición de Motivos de iniciativa con proyecto de decreto por el que se expide la Ley de Migración y se reforman, derogan y adicionan diversas disposiciones de la Ley General de Población.

Corte Interamericana de Derechos Humanos, Caso de la Masacre de Mapiripán vs. Colombia, serie C, núm. 122, 15 septiembre 2005. 
Esta revista forma parte del acervo de la Biblioteca Jurídica Virtual del Instituto de Investigaciones Jurídicas de la UNAM

- Caso de la Masacre de Pueblo Bello vs. Colombia, serie C, núm. 140, fondo, reparaciones y costas, sentencia de 31 de enero de 2006. - Caso Familia Pacheco Tineo vs. Bolivia, sentencia de excepciones preliminares. fondo, reparaciones y costas, serie C, núm. 272, 25 de noviembre de 2013.

- Caso Gelmán vs. Uruguay, serie C, núm. 221, fondo y reparaciones, sentencia del 24 de febrero de 2011.

-, Caso Mendoza y otros vs. Argentina, serie C, núm. 260, excepciones preliminares, fondo y reparaciones, sentencia del 14 de mayo de 2013. de 1988.

, Caso Vélez Loor vs. Panamá, serie C, núm. 218, sentencia de excepciones preliminares, fondo, reparaciones y costas, 23 de noviembre de 2010.

, Caso Vera Vera y otra vs. Ecuador, serie C, núm. 224, excepción preliminar, fondo, reparaciones y costas, sentencia de 19 de mayo de 2011. - Opinión Consultiva, OC-21/14, Los derechos y garantías de las niñas y niños en el contexto de la migración y/o necesidad de protección internacional, serie A, núm. 21, 19 de agosto de 2014.

, Opinión Consultiva, OC-18/13, Condición Jurídica y Derechos de los Migrantes Indocumentados, Corte Interamericana de Derechos Humanos, serie A, núm. 18, 17 de septiembre de 2003.

, Opinión separada del Juez Rodolfo E. Piza Escalante, Corte Interamericana de Derechos Humanos, Exigibilidad del Derecho de rectificación o respuesta (arts. 14.1, 1.1 y 2 Convención Americana sobre Derechos Humanos), Opinión Consultiva OC-7 /86, 29 de agosto de 1986, serie A, núm. 7. 